Document downloaded from:

http://hdl.handle.net/10251/63426

This paper must be cited as:

Paredes Arquiola, J.; Andreu Ȧlvarez, J.; Martín Monerris, M.; Solera Solera, A. (2010). Water Quantity and Quality Models Applied to the Jucar River Basin, Spain. Water Resources Management. 24(11):2759-2779. doi:10.1007/s11269-010-9578-z.

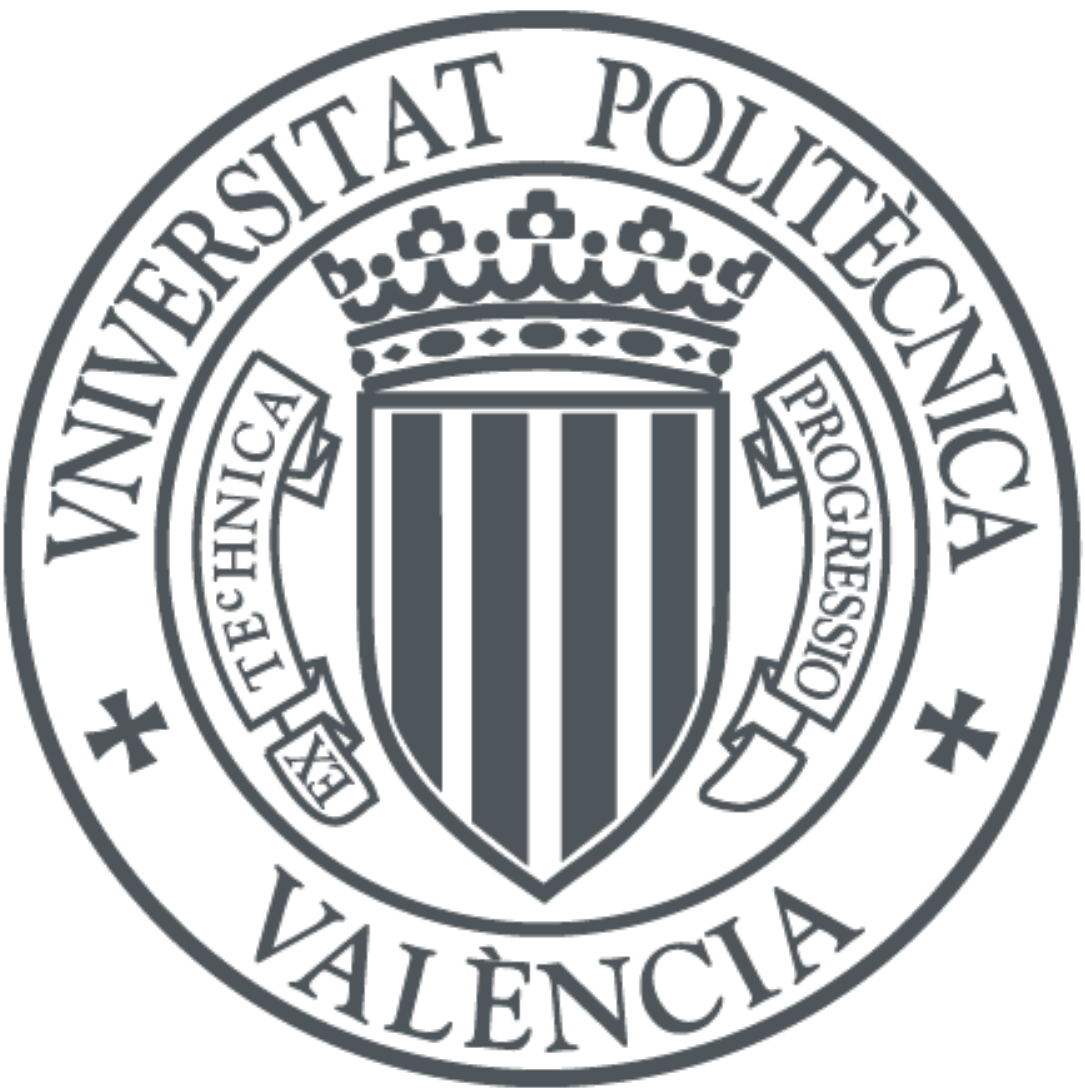

The final publication is available at

http://dx.doi.org/ 10.1007/s11269-010-9578-z

Copyright SPRINGER

Additional Information

"The final publication is available at Springer via http://dx.doi.org/ 10.1007/s11269-0109578-z". 


\title{
Water quantity and quality models applied to the Jucar river Basin, Spain.
}

\section{Javier Paredes-Arquiola ${ }^{1}$, Joaquín Andreu ${ }^{2}$, Miguel Martín-Monerris' ${ }^{2}$, Abel Solera ${ }^{2}$}

\begin{abstract}
Traditionally, water quality modelling has focused on modelling individual water bodies. However, water quality management problems must be analyzed at the basin scale. European Water Framework Directive (WFD) requires introducing physical, chemical and biological aspects into the management of water resources systems. Water quality modelling at a basin scale presents the advantage of incorporating in a dynamic way the relationships between the different elements and water bodies. Currently, there are few tools to deal with water modelling of water quality and management at the basin scale. This paper presents the development of a water quantity model and a water quality model for a very complex water resources system: the Júcar River Basin (Spain). The basin is characterized by a high degree of use of the water and by many water problems related to point and diffuse pollution, on top of a complex water quantity management of the basin. To deal with this problem, SIMGES (water allocation) and GESCAL (water quality) basin scale models have been used. Both are part of the Decision Support System AQUATOOL, one of the main instruments used in Spain in order to analyze water quantity and quality aspects of water resources systems for the compliance with WFD, as shown for the case of study.
\end{abstract}

KeyWords: Integrated water resources management; water quality; simulation models; decision support systems; pollutants; Jucar river basin.

\footnotetext{
${ }^{1}$ Assistant Professor, Institute of Water and Environmental Engineering. Technical University of Valencia. Postal Address: Universidad Politécnica de Valencia, Camino de Vera s/n 46022 Valencia (SPAIN) Fax: +34 963879618 Phone: +34 963879820. E-mail: jparedea@hma.upv.es ${ }^{2}$ Professor, Institute of Water and Environmental Engineering. Technical University of Valencia. Postal Address: Universidad Politécnica de Valencia, Camino de Vera s/n 46022 Valencia (SPAIN) Fax: +34 963879618 Phone: +34 963879820. E-mail: ximoand@upvnet.upv.es
} 


\section{Introduction.}

New water policies around the world, including the European Water Framework Directive (WFD) (EC, 2000), are demanding more integrated, participatory, sustainable, efficient, and equitable planning and management of water resources, and set the river basin as the adequate unit of analysis and solution (Andreu et al. 2008). Currently, WFD requires in the European Union the definition of environmental goals and of the program of measures to achieve these goals. These environmental objectives include ecological objectives, environmental flows, physical and chemical conditions of the water bodies, and other restoration measures.

In order to estimate the global effectiveness of the measures, an integrated visualization of the whole basin has to be used to take into account the interdependence between actions.

In this framework, water quality management is an essential task for preserving valuable water resources and facilitating sustainable socio-economic development in watershed systems (Huang and Xia, 2001; van Gils and Argiropoulos, 2004; Kotti et al., 2005; Qin and Huang, 2009). Sustainable development and rational use of the water resources require accounting for the relationship between water quantity and quality. Many instances can be found where water resources management neglects water quality aspects, or considers them only as restrictions. The necessity of considering both, water quantity and quality aspects, in a common strategy has been posed by several authors (Arnold and Orlob, 1989; Strzepek et al., 1989; Paredes and Lund, 2006). Since River basins often cover large areas with

complex interactions between water resources management activities, water uses and 
environment, tools are needed to assess the effects of planned measures (Loucks and Van Beek, 2005; Letcher et al. 2007; Koch and Grünewald, 2008).

To deal with this problem, some researchers have considered water quality aspects inside water management decision support systems (DSS). For example, de Azevedo et al. (2000) modified MODSIM water allocation model to include water quality constraints. Zhang et al. (2009) apply a model integrating hydrological processes, water allocation and water quality to the Jiaojiang River (China). Bhakdisongkhram et al. (2007) manipulate water quantity and quality to reduce environmental impacts in Mae Moh area (Thailand), assessing the alternatives through modelling water quantity and water quality.

This paper explains the performance of a water quantity model and a water quality model for the Júcar River Basin, in the east of Spain. The basin has water allocation problems due to a high degree of use of the water resources for agricultural purposes. On top of this, there are water quality problems due to point loads and diffuse sources. A water management model has been developed with SIMGES (Andreu et al. 1992). SIMGES is a flow simulation module for water resources management that provides the flows in rivers and other water bodies resulting from the allocation of water among uses and environmental requirements as a consequence of the operating rules that take into account water rights and priorities, as well as physical constraints (Andreu and Capilla, 1993). In order to simulate water quality associated with the water management simulations, a water quality model has been developed using GESCAL (Paredes et al, 2007). GESCAL is a water quality simulation module that allows simulation of water quality in all the water bodies of the basin, and for different management alternatives. Once GESCAL model has been calibrated, 
different alternatives can be evaluated to improve the water quality in critical points of the river. Both models are linked, in the sense that quality models developed with GESCAL, share the graphical interface for geo-referenced data management and analysis of results with SIMGES, as both are parts of the Decision Support System (DSS) Shell AQUATOOL

(Andreu et al, 1996). AQUATOOL is being used for Water Resources Planning and Management analysis in many Spanish basins, since it offers the possibility of relatively easy, systematic and homogeneous application of DSS over wide regions, and also provides guidance in the development of the DSS. Therefore, simulation of water quality can be performed immediately after the simulation of a water management alternative, providing information that helps to assess the alternative in terms of water quality.

\section{SIMGES: The flow simulation and water management module.}

As mentioned previously, SIMGES module is part of the DSS Shell AQUATOOL for the modelling and analysis of the integrated management of water resources systems (WRS). This tool has been widely applied in different Spanish basins and abroad. More complete descriptions of this model can be found elsewhere (Andreu et al., 1992). A brief description is included here to highlight the need for the integration of all the relevant elements that constitute a WRS at basin scale. SIMGES model is based on the conceptualization of a WRS using elements that represent river reaches, channels, reservoirs, aquifers, desalination plants, water uses of different kind (urban, agricultural, industrial, hydropower, etc.), direct use of treated wastewater, artificial recharge to aquifers, among other features of the basin. Also, the legal aspects and operating rules that must be taken into account for the allocation of water among the water uses and the environmental requirements are 
included, as well as the policies oriented to manage special situations like drought episodes. The resulting schematic representation of the WRS is transformed into a complex conservative flow network composed of arcs and nodes. Arcs are defined by the origin and final node, maximum and minimum flow, and unit cost of flow circulation, and represent, either real flows circulating through rivers, channels, etc., or virtual flows that are necessary to represent in an adequate way the physical restrictions, the management policies, and to account for nonlinearities. Mathematically, the simulation model is based on the resolution, for each time step (monthly time scale is used in this model), of this flow network. This defines an optimization problem that can be expressed by means of an objective function and a set of constraints:

$$
\begin{gathered}
\operatorname{Min} \sum_{i=1}^{m} \sum_{j=1}^{n} c_{i j} x_{i j} \\
\sum_{j=1}^{m} x_{i j}-\sum_{k=1}^{m} x_{k i}=0 \quad \forall i=1, \ldots, m \\
x_{i j} \geq l_{i j} \quad \forall i=1, \ldots, m \quad \forall j=1, \ldots, m \\
x_{i j} \leq u_{i j} \quad \forall i=1, \ldots, m \quad \forall j=1, \ldots, m
\end{gathered}
$$

Where $x_{i j}$ is the flow from node "i $i$ " to node " $\mathrm{j}$ "; $c_{i j}$ is the unit cost of the flow, $1_{i j}$ and $u_{i j}$ are the lower and upper flow limits for the arc from the node "i" to node " $\mathrm{j}$ ". This problem is efficiently solved with the Out of Kilter algorithm (Ford and Fulkerson, 1962). Some nonlinearities are directly accounted for in the problem formulation by means of piecewise approximation, and some others by means of successive approximations until convergence is reached. 
SIMGES model allows the creation of different models using a user-friendly graphic interface provided by the DSS shell AQUATOOL. Different elements can be considered for modelling WRS: Inflows or impaired flows; streams, rivers and artificial channels are modelled with flow elements; nodes represent junction points and are used to define the topology of the system, or to incorporate other elements as inflows, etc; reservoirs are nodes where storage is permitted; consumptive demands are defined by curves of monthly demand; demands surplus can be incorporated to the system trough return elements; each demand can be supplied from one or several intakes or sources; non consumptive demands (e.g., hydropower plants) are defined with objective monthly flows; and aquifers can be modelled using different approaches, from simple tank to complex distributed models (this is one of the main features of SIMGES).

The management of the system is incorporated into the model by means of different devices. Zoning and priority systems are defined for the reservoirs. Supplies among different demands are defined by another group of priorities. Besides the priorities system, the program has the possibility of defining rule curves for single reservoirs, or for groups of reservoirs. So, if the volume stored is less than the value defined in the curve then restriction coefficients can be applied for different elements such as: intakes, demands, channels, pumps, etc. Operation rules defined by rule curves are a versatile approach for defining the management policies of the systems.

As mentioned before, nonlinear processes such as evaporation, filtration, or aquifer models, which are not dealt by internal piecewise approximation, are solved with iterative resolution of the optimization problem. 
The optimal solution of flows constitute a solution for the allocation of water in the WRS within the time unit (i.e., month) that complies with the physical constraints, and satisfies adequately the legal rights and priority system, the environmental requirements, and the objective of water conservation, under normal situations, as well as under drought situations.

The resulting DSS can be used to assess different alternatives (or programs of measures in the WFD terminology), under different scenarios (including climate change scenarios), including sensitivity analyses, and risk assessment. All this analysis is facilitated by the graphically geo-referenced databases and the graphical results analysis included in AQUATOOL.

\section{GESCAL: Water quality modelling module.}

The recently developed tool, GESCAL, is a generic module that allows the development of water quality models for almost any basin. Previously, a flow simulation model has to be build with the module SIMGES. This tool is not for a specific case, but can be used for any water resources system. Stream flows and storages estimated by the flow simulation model can be used as inputs to the water quality model. Although water quality has been considered in all the elements of the simulation models, only in streams and reservoirs (or lakes) have physical-chemical processes been taken into account.

GESCAL allows modelling the following constituents:

- Temperature. Water temperature modelling employs the equilibrium temperature approach proposed by Edinger and Geyer (1965). Due to the influence of the temperature on many processes, it is important to take it into account. On the other 
hand, there is a general difficulty to obtain good meteorological data on a basin scale for water temperature modelling. Thus, in GESCAL the temperature can be modelled, or it can be incorporated as an input in each element. This input temperature, or the modelled one, is, later on, used to correct the coefficients of the other processes.

- Arbitrary constituents. Defined as the ones for which degradation can be modelled as a first order kinetic and/or with a sedimentation velocity. The maximum number of arbitrary constituents is limited only by computational capacity.

- The dissolved oxygen can be considered with three possible levels of complexity. The simplest level considers CBOD and dissolved oxygen. The second level considers the cycle of nitrogen and the effect over the dissolved oxygen. Ammonia, nitrites and nitrates are considered. Finally, the last level of complexity allows modelling CBOD, nitrogen cycle, phytoplankton, and phosphorous, and their relationships and their effects over the dissolved oxygen. Figure 1 shows a scheme of the processes considered.

\section{Modelling streams and rivers.}

Dispersion and advection are the physical processes considered when modelling water quality of rivers. One-dimensional and pseudo-stationary conditions are assumed for water quality in rivers. For each one of the months simulated with the water quantity simulation model, the water quality model estimates the water quality. The model is pseudo-stationary because, for each month, the mass balance equations are solved iteratively until the stationary water quality estimates for the river, with given loads, flow, input concentrations, 
etc., converge. Hydraulic aspects in the rivers are estimated by power relations or Manning equations. Point loads and diffuse pollution elements can be considered, and the hydraulic relationship with aquifers is considered by filtration or gaining relationships. Figure 2 represents a scheme of the model for rivers.

For each constituent, the following equation is formulated:

$0=\frac{d}{d x}\left(E \frac{d C}{d x}\right)-\frac{d(u C)}{d x}+\frac{S_{d}+C_{e} q_{e}-C q_{s}+\sum S_{i}}{V}$

Where: E represents dispersion $\left(\mathrm{m}^{2} \mathrm{~d}^{-1}\right)$; $\mathrm{C}$ concentration of constituent $(\mathrm{mg} / \mathrm{l}) ; \mathrm{C}_{\mathrm{e}}$

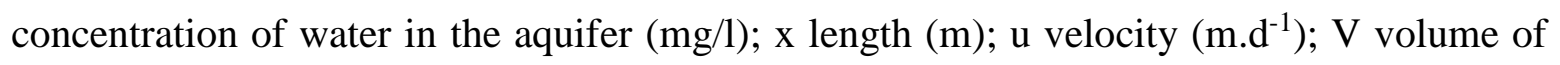
the differential element $\left(\mathrm{m}^{3}\right) ; \mathrm{q}_{\mathrm{e}}$ is the flow from the aquifer $\left(\mathrm{m}^{3} \mathrm{~d}^{-1}\right) ; \mathrm{q}_{\mathrm{s}}$ is seepage filtration from the river to the aquifer $\left(\mathrm{m}^{3} \mathrm{~d}^{-1}\right) ; \mathrm{S}_{\mathrm{d}}$ diffuse pollution $(\mathrm{g} / \mathrm{d}) . \sum \mathrm{S}_{\mathrm{i}}(\mathrm{g})$ represents physical chemical processes that affect each constituent. This term is explained, for each constituent modeled, in annex A.

The differential equations are solved with a finite difference approach, requiring fragmentation of the river into differential elements. It is assumed that diffuse pollution and hydraulic relationships with any aquifer are spatially uniform. The numerical resolution of the finite difference consists in resolving a tri-diagonal linear system of equations.

\section{Reservoirs and lakes water quality modelling}

Reservoir and lake water quality can be approached by a two-layer model representing epilimnion and hypolimnion (see figure 3). Alternatively, a Continuous Stirred Tank Reactor can be considered for modelling well-mixed reservoirs. Due to the evolution of the storage in the reservoirs, the water quality model is dynamic in time. The user must 
introduce as an input, for each reservoir, the monthly distribution of the depth of the thermocline and the distribution of inflows and outflows for each layer. The program, then, estimates if the volume in each month is enough to allow stratification. For each reservoir, the water quality can be modelled as only one layer for some months, and as two layers for other months. In this last case, diffusion between the two layers is considered. Equations 3 and 4 represent the general formulations for any constituent.

Since SIMGES only provides monthly results, it is assumed that the evolution of the storage follows a linear distribution within the month. Moreover, since reservoirs are dynamic, and downstream rivers are stationary, it is assumed that the outflow concentrations during a month are an average of all the concentrations estimated for the reservoir for that month.

The equations that are used to model the processes are the following:

$$
\begin{aligned}
& \frac{d\left(V_{1} C_{1}\right)}{d t}=Q_{1 e} C_{e}-Q_{1 s} C_{1}+E_{12}^{\prime}\left(C_{2}-C_{1}\right)+\sum S_{i 1} \\
& \frac{d\left(V_{2} C_{2}\right)}{d t}=Q_{2 e} C_{e}-Q_{2 s} C_{2}+E_{12}^{\prime}\left(C_{1}-C_{2}\right)+S+\sum S_{i 2}
\end{aligned}
$$

Where: sub-index "1" represents epilimnion and sub-index "2" hypolimnion; $\mathrm{V}_{1}$ and $\mathrm{V}_{2}$ are the volume of each layer $\left(\mathrm{m}^{3}\right) ; \mathrm{C}_{1}$ and $\mathrm{C}_{2}$ are the concentration of each layer $\left(\mathrm{mg} . \mathrm{l}^{-1}\right) ; \mathrm{C}_{\mathrm{e}}$ is the inflow concentration $\left(\mathrm{mg} . \mathrm{l}^{-1}\right) ; \mathrm{t}$ represents time; $\mathrm{Q}_{1 \mathrm{e}}$ and $\mathrm{Q}_{2 \mathrm{e}}$ are inflows in each time interval $\left(\mathrm{m}^{3} \mathrm{~d}^{-1}\right) ; \mathrm{Q}_{1 \mathrm{~s}}$ and $\mathrm{Q}_{2 \mathrm{~s}}$ are outflows in each time interval $\left(\mathrm{m}^{3} \mathrm{~d}^{-1}\right) ; \mathrm{S}$ is sediment flux $(\mathrm{gr} / \mathrm{d}) ; \mathrm{S}_{\mathrm{i} 1}$ and $\mathrm{S}_{\mathrm{i} 2}$ are the terms representing the processes modelled, depending on the constituent considered (see annex A). $\mathrm{E}_{12}^{\prime}$ represents dispersion coefficient between both layers $\left(\mathrm{m}^{3} \mathrm{~d}^{-1}\right)$. It must be noticed that units have been written assuming time interval of one day. 


\section{Modelling other elements}

For the other elements considered in the SIMGES module, water quality has been considered in different ways. For some elements, such as hydroelectric power plants, it is assumed that water quality is not modified. In nodes, complete mixing of all the inflows is assumed. For the inflow elements, the user must introduce concentration time series (monthly) for each constituent. It is possible to incorporate effluents from water treatment plants, or elements of pollution in the intakes and in the returns of demands to the system. Finally, it is assumed that the water quality of the aquifers remains constant in time, and it is defined as an input of the model.

The program has been developed in FORTRAN language, and can be used in personal computers with Windows operating system. Moreover, a graphic interface has been programmed in Visual Basic 6, as a module of the DSS shell AQUATOOL, facilitating and enhancing the modelling and analysis processes.

\section{Case of study: the Júcar river basin.}

\section{Description of the water resources system.}

The Júcar river basin is located in the east of Spain (see figure 4). It has an area of 21,632 $\mathrm{km}^{2}$, a main stem length of approximately $500 \mathrm{~km}$, and an average precipitation of 510 $\mathrm{mm} /$ year. Urban water use is $118.64 \mathrm{hm}^{3} /$ year for $1,030,979$ people. Irrigated surface is $187,855 \mathrm{ha}$, consuming $1,394 \mathrm{hm}^{3} /$ year. It is a much regulated basin, with a total reservoir capacity of $2,643 \mathrm{hm}^{3}$. The management of the system is very complex, with many users, and considerable hydrologic variability. 
Water quality problems appear in the medium and lower parts of the basin. In the medium part, irrigation activities are increasing nitrate concentrations in groundwater and, consequently, also in surface water. Since there are some intakes for urban demands, this is already a problem, and could get worse in the medium and long terms. In the lower part of the river, water quality gets worse. This is where a great part of urbanized, industrial, and agricultural pressures are located. In this part of the river, dissolved oxygen concentrations are usually less than $2 \mathrm{mg} / \mathrm{l}$, ammonia is between 0.1 to $1.2 \mathrm{mg} / \mathrm{l}$, and nitrates over $30 \mathrm{mg} / \mathrm{l}$ $\mathrm{NO}_{3}$. Reservoirs in the Júcar basin (except two that are located in tributaries and not considered in this study), have a good water quality with an oligo-mesotrophic level.

Prior to modelling, an analysis of water quality in the basin was made. This water quality diagnostic has allowed establishing the main sources of environmental pressure in the basin, to define the calibration periods, and to characterize the elements for modelling water quality.

\section{Modelling}

The model was focused on the main course of the Júcar River and its tributary Cabriel River with an existing water quantity simulation model developed with SIMGES. This model was modified to adapt it for water quality modelling. These modifications included: finer river discretization, and consideration of non regulatory reservoirs (e.g., small diversion dams).

To develop and calibrate the water quality model, water monitoring data were used. Additional information in GIS format was: spills, agricultural areas, geology of the basin, land uses, weirs, etc. This information was provided by Júcar River Basin Agency. 
Finally, with the water quality monitoring network data, and other data gathering campaigns, an integral water quality module was set up for the following constituents: conductivity, suspended solids, CBOD, dissolved oxygen, ammonium, and nitrates. Dissolved oxygen was modelled with the second level of complexity mentioned, considering the effect of the nitrogen cycle. Figure 5 shows the scheme of the Júcar river model.

\section{Calibration}

The calibration procedure was performed in several steps. In a first phase, the water quantity management model was forced to reproduce historical water flows in the rivers and volumes in the reservoirs. This task was done using management options of SIMGES such as priorities in reservoirs and demands, definition of storage priority zones in reservoirs, and other operation rules.

In a second phase, water quality model was calibrated. Several parameters were tuned in order to match simulated and observed values at some locations of the basin. More than twenty stream elements and five reservoirs were calibrated. Figures 6 to 9 show calibration results of two stream elements and one reservoir. One of the stream elements shown is in the middle part of the river, with low pollution, and the other is in the final part, with a higher pollution. Water quality models for whole basins imply a great number of parameters to calibrate. In this case, parameters of the model were tuned by trial and error, trying to maintain homogeneity among areas of similar morphology or river and environmental pressures. Many streams are in natural conditions in reference to constituents such as oxygen, ammonia and phosphorous. In these areas, mainly located in 
the high and medium part of the basin, concerns are conductivity and nitrates. Salinity of the water in Júcar River is mainly produced by geology of the basin, and in the model it has been considered as a conservative process. The use of conductivity as a tracer in the basin has allowed discovering some problems in the data. Matching of concentrations of the constituents depends mainly on a good agreement of the surface and groundwater runoff because the main part of the nitrates comes from contaminated aquifers. A clear example of this situation is the area downstream of Alarcon reservoir, where the polluted aquifer of La Mancha increases nitrate concentrations in the river.

The parts of the river that required a special focus during the calibration are located downstream of the greater effluent discharges of the basin. Mainly in the lower part of the river, the last $50 \mathrm{Km}$, where pollution affects mostly all the conventional constituents as dissolved oxygen, BOD, ammonia, nitrates, organic nitrogen, suspended solids, and phosphorous.

Table 1 shows values of tuned parameter, grouped by zones of the basin. As it can be seen, the zones of the headwaters and the medium part of the river have low parameter values. In the low part of the river, the parameters achieve the maximum values, specially nitrification rates and organic matter degradation rates.

Finally, sediment velocities achieve maximum values in the ponds at the diversion weirs areas. Downstream of the discharge point of the effluent of the city of Alzira (point load), three weirs are located with the purpose of diverting water for agricultural use. In these ponds of the weirs, the sedimentation of the particulate matter discharged by the waste water of Alzira is very high, mainly in the first weir, the critical point of the basin. 
Afterwards, sensitivity analysis was performed individually for all the elements, and for all the calibrated coefficients. Finally, verification was carried out to test the behaviour of all elements working together. This test is used to detect global problems with the model. Figure 10 represents the minimum, maximum, and average values along the river for observed and calculated values of conductivity and nitrates.

\section{Analysis of results}

This study examined different future situations of the water resources system, water treatment possibilities, and other actions to improve the water quality in the lower part of the river. These were translated into different scenarios. Each scenario was simulated using hydrological inflows for the period 1985 -2001. This period includes a wet period and two drought periods (1993-1995 and 1998-2001).

The main pollution source is a group of urban waste water loads in the lower part of the river. Currently, a Plan has been developed in order to improve the treatment of several wastewater treatment plants (WWTP) through the basin. One goal of the study was to estimate the effect of the new Plan on the water quality of the river. Using GESCAL, it has been estimated that dissolved oxygen will improve in several points of the lower part. At the critical point of the river, dissolved oxygen concentration could change from $3.5 \mathrm{mg} / \mathrm{l}$ to $7.6 \mathrm{mg} / \mathrm{l}$ on average. The model also quantified the average reductions in suspended solids (from 28 to $9 \mathrm{mg} / \mathrm{l}$ ) and ammonium (from 1.81 to $0.12 \mathrm{mg} / \mathrm{l}$ ). Figures 10 and 11 reflect the comparative concentrations of current dissolved oxygen and Total Suspended Solids versus the ones obtained for the Plan stages. 
The second aspect studied, was a comparison of the system in the current, medium and long term scenarios, as defined by the Júcar River Basin Plan (CHJ 1998). These situations differ due to changes in future demands in the system, which affect flows in the river, reservoir storages, irrigation returns, etc.; and, consequently, it also affects water quality. The medium term scenario considers modernization of traditional irrigated areas (substitution of canals by pipes, and changing the irrigation procedures from furrow to drip irrigation), a water transfer to a neighbour basin, and the increase of some demands. The simulation of this scenario reflects maintenance of current water quality concentrations in the river. However, for the long term, with a significant increase of several demands, results show a decrease in water quality in the overall system in critical situations. Moreover, the model has allowed estimating that, in the reservoirs, the phosphorous contents will increase, and so will the trophic state, if water demands increase substantially. Figure 12 shows the average concentrations of nitrates estimated with the model for the current, medium, and long term scenarios.

Finally, for all the scenarios previously defined, environmental, incremental, and dilution flows were estimated for each alternative. These additional flows were estimated under the water quality criteria for aquatic life considering dissolved oxygen as the critical constituent. Results show that the effect of these environmental flows on the reliability of the supplies to demands is very low. In the case of the traditional users, this loss of reliability is less than $2 \%$. For all the alternatives, it was estimated that $1.9 \mathrm{~m}^{3} / \mathrm{s}$ of flow increment is enough to achieve good water quality standards for aquatic life. In the critical summer months (i.e., July, August, and September) this quantity must be increased, depending on the scenario. 


\section{Conclusions}

This paper presents the application of a water quality model and a water quantity model to a complex water resources system, the Júcar River Basin. Whereas few real cases of water management and quality models at basin scale have been reported, in this paper one of such cases is presented, and the usefulness of the results is quite obvious, since they are being used for water resources planning under the Water Framework Directive objectives.

Júcar River basin is a very complex case, where diffuse and point pollution coincide with water quantity management problems. The linked water quantity and water quality models in this study are being used by Júcar Basin Authority to test different measures in the water basin plan. Despite the difficulty of building a model at basin scale, this kind of models have a great potential in its use as decision support systems.

This is the first application of a new water quality module GESCAL. This tool expands the AQUATOOL DSS modelling framework to achieve linking water quantity and quality modelling at basin scale. This module allows modelling of temperature, arbitrary constituents, dissolved oxygen and eutrophication processes. The main advantages of GESCAL are the variety of constituents that can be modelled, the integration with the water management module, its modular structure, and the integration of all the elements of a basin and their interdependences. Its integration in the AQUATOOL DSS environment provides easiness of use and of result display and analysis. Currently, this module is also being used by the Duero and Tajo river Basin Agencies in order to develop their Basin Plans for the WFD implementation. 
In the future, the module will be expanded to incorporate new contaminants and other water quality aspects, such as sediments, non stationary river hypothesis, and other, to overcome current limitations. Also, there is an ongoing project in order to couple the water allocation simulation and the water quality simulation models in such a way that water quality will be also considered in the operating rules and decisions for each time interval (i.e., month).

\section{Acknowledgments:}

This study was supported by funds from Júcar River Basin Agency (Spanish Ministry of Environment), from the Spanish Ministry of Education and Culture (project "Desarrollo de elementos de un sistema soporte de decisión para la gestión de recursos hídricos", HID1999-0656), and from the European Union (project "SEDEMED-Sécheresse et Desertification dans les bassins méditerranées”, ref. 2002-024.4-1084).

The authors appreciate the collaboration of the Júcar River Basin Agency for making available all the data needed for the work. 


\section{References}

Andreu J, Capilla J, Ferrer J (1992) Modelo Simges de simulación de la gestión de esquemas de recursos hídricos, incluyendo utilización conjunta, Serv. Publ. UPV, Valencia, Spain.

Andreu J, Capilla J (1993) Optimization and Simulation Models Applied to the Segura Water Resources System, in Stochastic Hydrology in Water Resources Systems: Simulation and Optimization, ed. by Marco, J., R. Harboe and J.D.Salas, Kluwer Academic.

Andreu J, Capilla J, Sanchis E. (1996) AQUATOOL: A generalized decision support-system for waterresources planning and operational management. Journal of Hydrology. 177 (1996) 269-291.

Andreu J, Solera A, Paredes J, Pérez MA, Pulido M (2008) Decision support tools for policy making in European Water Research Day (Zaragoza), European Communities, Sept. 2008.

Arnold U, Orlob GT (1989) Decision support for estuarine water quality management. J. Water Resour. Plng. and Mgmt., ASCE, 115(6), 775-792.

Bhakdisongkhram T, Koottated S, and Towprayoon S (2007) A Water model for water and environmental management at Mae Moh area in Thailand. Water Resour. Manag. 21:1535-1552.

CHJ (1998) Plan Hidrológico de la Cuenca del Júcar. Confederación Hidrográfica del Júcar. Ministerio de Medio Ambiente, Spain.

de Azevedo LGT, Gates TK, Fontane DG, Labadie JW, Porto RL (2000) Integration of water quantity and quality in strategic river basin planning. J. Water Resour. Plng. and Mgmt., ASCE, 126(2), 85-97

EC (2000) Directive 2000/60/EC of the European Parliament and of the Council, of 23 October 2000, establishing a framework for Community action in the field of water policy. Official Journal of the European Commission, L 327/1,22.12.2000

Edinger JE, Geyer JC (1965) Heat exchange in the environment. Department of Sanitary engineering and Water resources, Research Project No. 49. The John Hopkins University. Baltimore. Maryland.

Ford CR, Fulkerson DR (1962) Flow in networks, Princeton University Press, Princeton, NJ, pp 194.

Huang GH, Xia J (2001) Barriers to sustainable water-quality management. J .Environ. Manag. 61(1):123.

Koch H, Grünewald U (2009) A comparasion of modelling systems for the development and revision of water resources management plans. Water Resour. Manag. 23:1403-1422.

Kotti ME, Vlessidis AG, Thanasoulias NC, Evmiridis NP (2005) Assessment of river water quality in Northwestern Greece. Water Resour. Manag. 19(1):77-94

Letcher R, Croke B, Jakeman A (2007) Integrated assessment modelling for water resources allocation and management: a generalised conceptual framework. Environ. Model. Softw. 22(5):733-742. doi:10.1016/j.envsoft.2005.12.014

Loucks DP, van Beek E (2005) Water resources systems planning and.management - an introduction to methods, models and applications. UNESCO, Paris.

Paredes J, Lund J (2006) Refill and drawdown rules for parallel reservoirs: quantity and quality. Water Resour. Manag. 20: 359-376. 
Paredes J, Andreu J, Solera A (2007) Manual del programa Gescal de la simulación de la calidad del agua. Universidad Politécnica de Valencia.

Qin XS, Huang GH. (2009) An Inexact change-constrained quadratic programming model for stream water quality management Water Resour. Manag. 23:661-695.

Strzepek K, García L, Over T (1989) MITSIM 2.1 river basin simulation model, user manual. Center for Advanced Decision Support for Water and Environmental Systems, University of Colorado, Boulder, Colorado.

van Gils JAG, Argiropoulos D (2004) Axios river basin water quality management. Water Resour. Manag .5(3-4):271-280.

Zhang W, Wang Y, Peng H, Li Y, Tang J, Wu B (2009) A coupled water quantity-quality model for water allocation analysis. Water Resour. Manag. Published on line: 27 May 2009. 


\section{Annex A. Water quality Formulation}

Temperature

$\sum S_{i}=\phi_{n e t}=K_{e q}\left(T_{e q}-T\right)$

Arbitrary constituent

$\sum S_{i}=-K\left(\theta^{T-20}\right) C-\frac{V S}{h} C$

Biochemical oxygen demand

$\sum S_{i}=-K_{d} \theta_{d}^{T-20} \frac{O}{O+K_{d 1 / 2}} L-\frac{V S_{L}}{h} L$

Organic nitrogen

$\sum S_{i}=-K_{\text {Noa }} \theta_{\text {noa }}^{T-20} N_{o}-\frac{V S_{N o}}{h} N_{o}+r_{n a} K_{\text {resp }} \theta_{\text {resp }}^{T-20} A$

Ammonia

$$
\sum \mathrm{S}_{\mathrm{i}}=+K_{\text {Noa }} \theta_{\text {Knoa }}^{T-20} N_{o}-\left(K_{\text {Nai }} \theta_{\text {nai }}^{T-20} \frac{O}{O+K_{n 1 / 2}}\right) N_{a}+-r_{n a} F_{n} K_{g}^{\prime} A
$$

Nitrates

$$
\sum S_{i}=\left(K_{N a i} \theta_{n a i}^{T-20} \frac{O}{O+K_{n a i 1 / 2}}\right) N_{a}-\left(K_{n o 3} \theta_{n o 3}^{T-20} \frac{O+K_{n o 31 / 2}}{O}\right) N_{o 3}-r_{n a}\left(1-F_{n}\right) K_{g}^{\prime} A
$$

Chlrophyll a

$\sum S_{i}=+\left[K_{g}^{\prime}-K_{r e s p} \theta_{r e s p}^{T-20}\right] A-\frac{V S_{A}}{h} A$ 


$$
\begin{aligned}
& K_{g}^{\prime}=K_{g \max } \cdot \theta_{g}^{T-20} \cdot F_{l} \cdot F_{N} \\
& F_{N}=\operatorname{Min}\left(\frac{N_{a i o 3}}{N_{a i o 3}+K_{N F 1 / 2}} ; \frac{P}{P+K_{P 1 / 2}}\right) \\
& F L=\frac{e \cdot f}{K e \cdot H_{1}} \cdot\left(e^{-I_{0} \cdot \frac{A t I_{o}}{I_{s a t}} \cdot e^{-K e \cdot H_{1}}}-e^{-I_{0} \cdot \frac{A t I_{o}}{I_{s a t}} \cdot e^{-K e \cdot 0}}\right) \\
& K e=K e_{0}+\alpha_{a t} \cdot A \text { (11) }
\end{aligned}
$$

Organic Phosphorous

$$
\sum S_{i}=-K_{m p} \theta_{m p}^{T-20} P_{o r}+f_{p} r_{p a} K_{r e s p} \theta_{r e s p}^{T-20} A-\frac{V S_{o r}}{h} P_{o r}
$$

Soluble Reactive Phosphorous

$\sum S_{i}=+K_{m p} \theta_{m p}^{T-20} P_{o r}-r_{p a} K_{g}^{\prime} A++\left(1-f_{p}\right) r_{p a} K_{r e s p} \theta_{r e s p}^{T-20} A$

\section{Dissolved Oxygen}

$$
\begin{aligned}
& \sum S_{i}=+K_{a} \theta_{K a}^{T-20}\left(O_{\text {sat }}-O\right)-K_{d} \theta_{d}^{T-20} L- \\
& -r_{a}\left(K_{N a i} \theta_{\text {nai }}^{T-20} \frac{O}{O+K_{n 1 / 2}}\right) N_{a}+ \\
& +r_{\text {ocrec }}\left(K_{g \text { max }} \theta_{g}^{T-20} F_{l} \operatorname{Min}\left(\frac{N_{\text {aio } 3}}{N_{\text {aio } 3}+K_{N F 1 / 2}} ; \frac{P}{P+K_{P 1 / 2}}\right)\right) A-r_{\text {oresp }} K_{\text {resp }} \theta_{\text {resp }}^{T-20} A
\end{aligned}
$$


$\alpha_{\text {at }}$ specific extinction coefficient for chlorophyll a $\left(\mathrm{L} \mathrm{mg}^{-1} \mathrm{~m}^{-1}\right)$

$\theta_{\text {ij }}$ temperature correction coefficient;

A chlorophyll a concentration $\left(\mathrm{mg} \mathrm{l}^{-1}\right)$;

C constituent concentration $\left(\mathrm{mgl}^{-1}\right)$;

f fotoperiod

Fl atenuation light factor;

$\mathrm{F}_{\mathrm{N}}$ nutrient limit factor;

$F_{n}$ preference factor for ammonia;

$f_{p}$ factor for organic phosphorous produced for phytoplankton respiration;

$h$ depth of the water body $(m)$;

I light intensity (langleys);

Io surface light intensity (langleys/d);

Is saturation light intensity (langleys);

$\mathrm{K}$ rate coefficient of arbitrary constituent degradation $\left(\mathrm{d}^{-1}\right)$;

$\mathrm{K}_{\mathrm{a}}$ rate coefficient of reaireation $\left(\mathrm{d}^{-1}\right)$;

$K_{d}$ rate coefficient of CBOD breakdown $\left(d^{-1}\right)$;

$K_{e}$ extintion coefficient $(1 / \mathrm{m})$;

$\mathrm{Ke}_{0}$ background extinction coefficient $\left(\mathrm{m}^{-1}\right)$;

Keq Heat interchange coefficient $\left(\mathrm{Wm}^{-2} \mathrm{o}^{-1}\right)$;

$\mathrm{K}_{\mathrm{g}}^{\prime \prime}$ rate coefficient for phytoplankton growth $\left(\mathrm{d}^{-1}\right)$;

$\mathrm{K}_{\mathrm{gmax}}$ rate coefficient for maximum phytoplankton growth $\left(\mathrm{d}^{-1}\right)$;

$K_{m p}$ Organic Phosphorous mineralization parameter $\left(\mathrm{d}^{-1}\right)$;

$\mathrm{K}_{\mathrm{n} 1 / 2}$ Semisaturation constant for nitrogen $\left(\mathrm{mg}^{-1}\right)$;

$\mathrm{K}_{\mathrm{Nai}}$ half saturation for nitrification $\left(\mathrm{d}^{-1}\right)$;

$\mathrm{K}_{\mathrm{NF} 1 / 2}$ half saturation for nitrogen uptake $\left(\mathrm{mg} \mathrm{|}^{-1}\right)$;

$K_{\text {noa }}$ rate coefficient for ammonification $\left(d^{-1}\right)$;

$\mathrm{K}_{\text {no3 }}$ rate coefficient for denitrificaton $\left(\mathrm{d}^{-1}\right)$;

$\mathrm{K}_{\text {No31/2 }}$ half saturation for dependene of denitrification on dissolved oxygen $\left(\mathrm{mg} \mathrm{l}^{-1}\right)$;

$\mathrm{K}_{\mathrm{p} 1 / 2}$ half saturation for phosphorous uptake $\left(\mathrm{mgl}^{-1}\right)$;

Kresp rate coefficient for phytoplankton death and respiration $\left(\mathrm{d}^{-1}\right)$;

L Biochemical oxygen demand $\left(\mathrm{mg} \mathrm{l}^{-1}\right)$;

$\mathrm{N}_{\mathrm{a}}$ ammonium $\left(\mathrm{mg} \mathrm{l}^{-1}\right)$;

$\mathrm{N}_{\text {aio3 }}$ inorganic concentration $\left(\mathrm{mgl}^{-1}\right)$;

$\mathrm{N}_{\mathrm{o}}$ organic nitrogen $\left(\mathrm{MT}^{-1}\right)$;

$\mathrm{N}_{\circ 3}$ nitrate concentration $\left(\mathrm{mgl}^{-1}-\mathrm{N}\right)$;

$\mathrm{P}$ concentration of dissolved reactive phosphorous $\left(\mathrm{mg}^{-1}\right)$

$\mathrm{P}$ or concentration of organic phosphorous $\left(\mathrm{mgl}^{-1}\right)$;

O dissolved oxygen concentration $\left(\mathrm{mgl}^{-1}\right)$;

Osat dissolved oxygen concentration at saturation $\left(\mathrm{mgl}^{-1}\right)$;

$r_{a}$ stoichiometric ratio of oxygen to nitrogen for nitrification $(\mathrm{mgO} / \mathrm{mgN})$; 
$r_{n a}$ factor of conversion of nitrogen to chorophyll a $(\mathrm{mgN} / \mathrm{mgA})$;

$r_{\text {ocrec }}$ rate of oxygen produced for phytoplankton growth $\left(\mathrm{d}^{-1}\right)$;

roresp rate of oxygen consumed for phytoplankton death and respiration $\left(\mathrm{d}^{-1}\right)$;

$r_{\mathrm{pa}}$ factor of conversion of phosphorous to chorophyll a (mgP/mgA);

$T$ temperature of the water body $\left({ }^{\circ} \mathrm{C}\right)$;

$\mathrm{T}_{\text {eq }}$ equilibrium temperature of the water body $(\stackrel{\circ}{\circ})$;

VS sedimentation rate $\left(\mathrm{m} \mathrm{d}^{-1}\right)$;

$\mathrm{VS}_{\mathrm{A}}$ sedimentation rate of chlorophyll a $\left(\mathrm{m} \mathrm{d}^{-1}\right)$;

VS $\left\llcorner\right.$ sedimentation rate of $C B O D\left(\mathrm{~m} \mathrm{~d}^{-1}\right)$;

$\mathrm{VS}_{\mathrm{NO}}$ sedimentation rate of organic nitrogen $\left(\mathrm{m} \mathrm{d}^{-1}\right)$;

$\mathrm{VS}_{\text {or }}$ sedimentation rate of organic phosphorous $\left(\mathrm{m} \mathrm{d}^{-1}\right)$; 


\section{Figures}

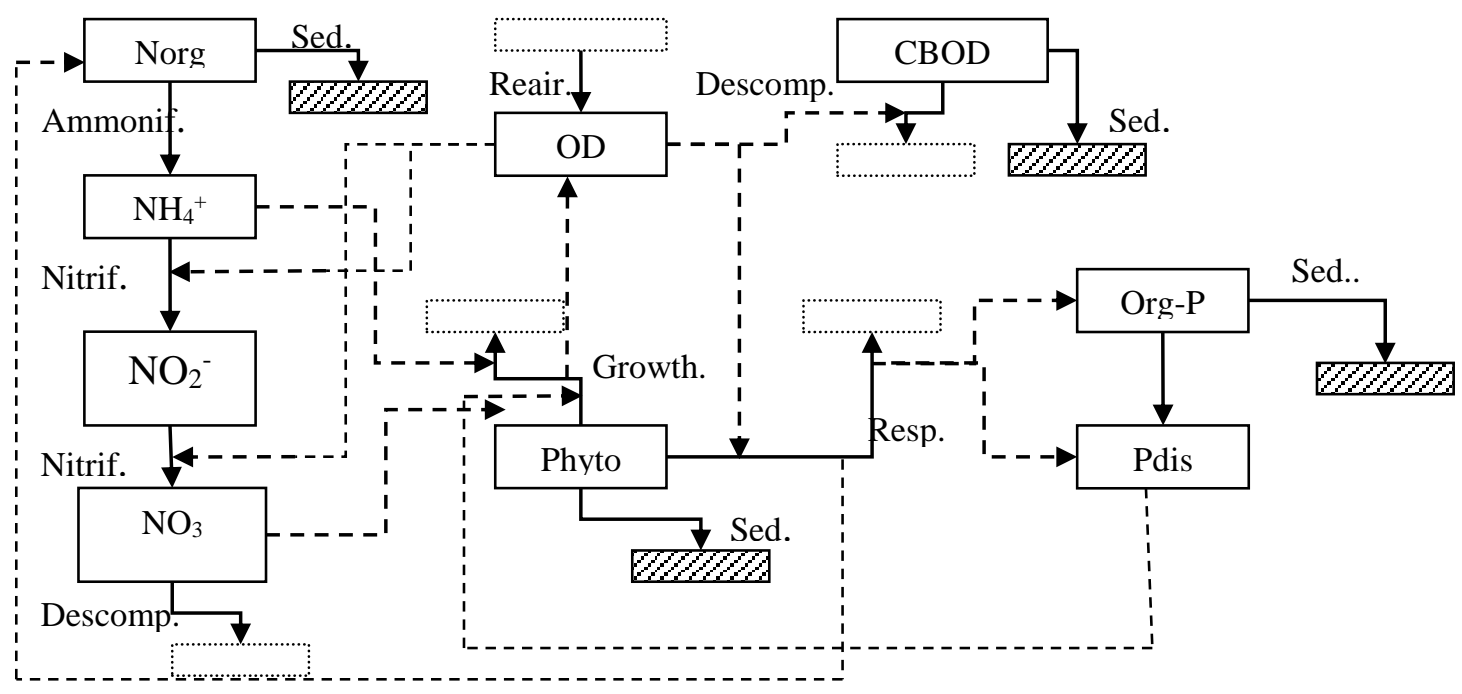

Figure 1. Processes considered in the eutrophication option.

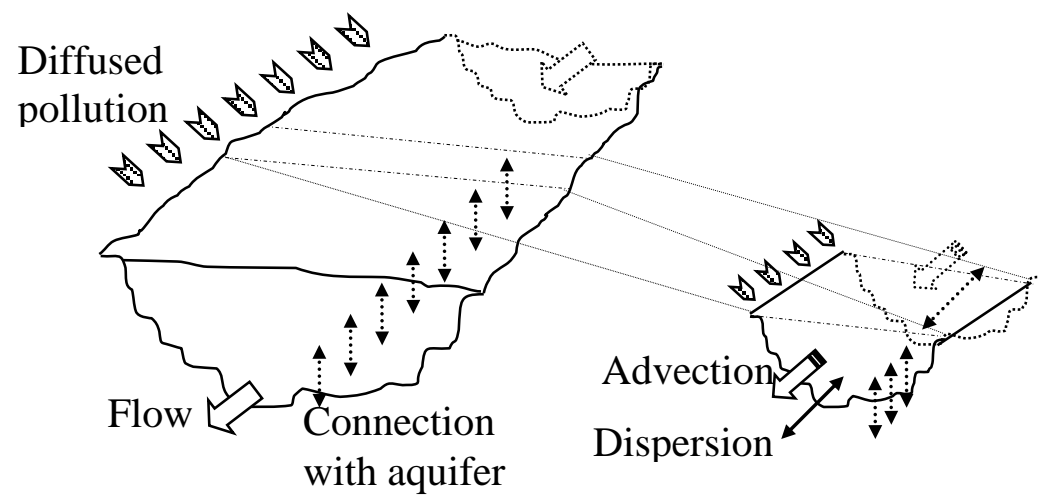

Figure 2. Discretized stream system 


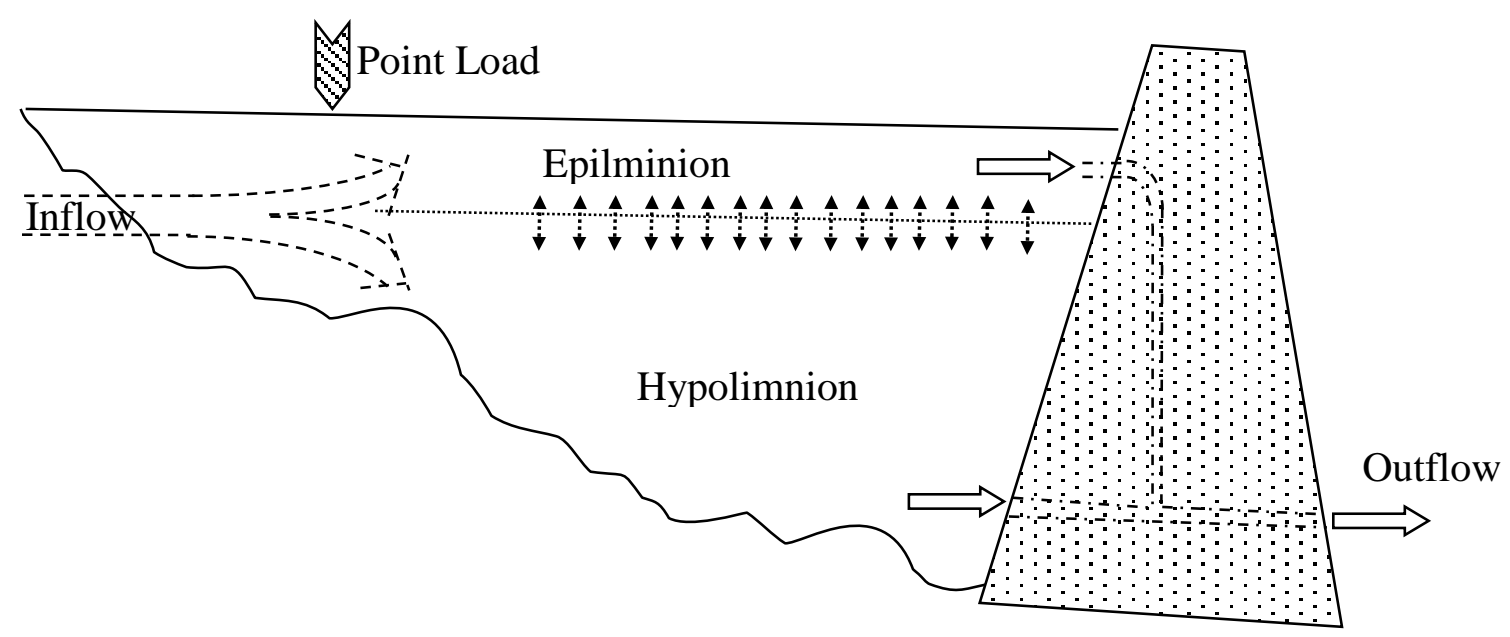

Figure 3. Reservoir System

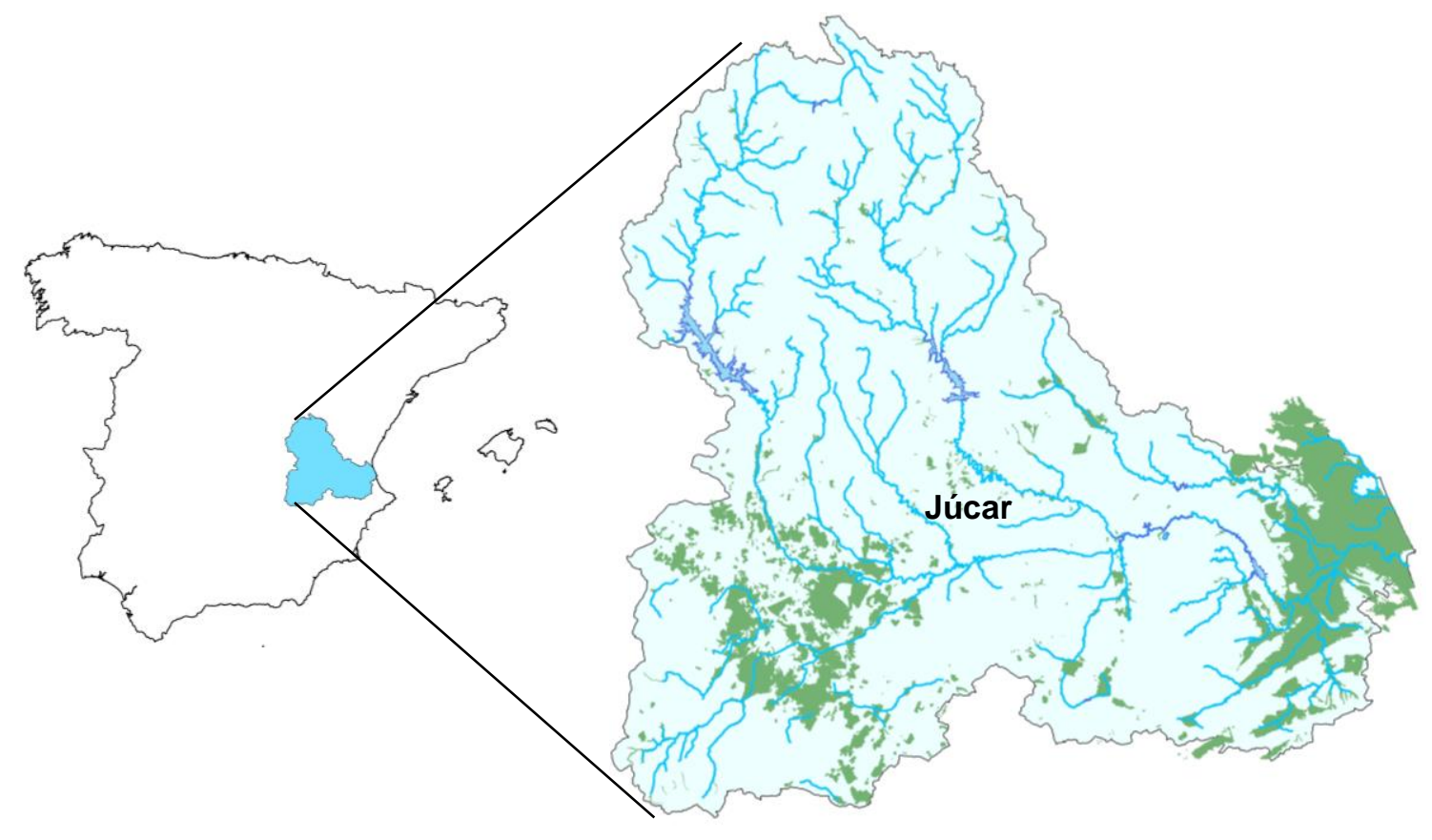

Figure 4. Location of the Júcar River Basin 


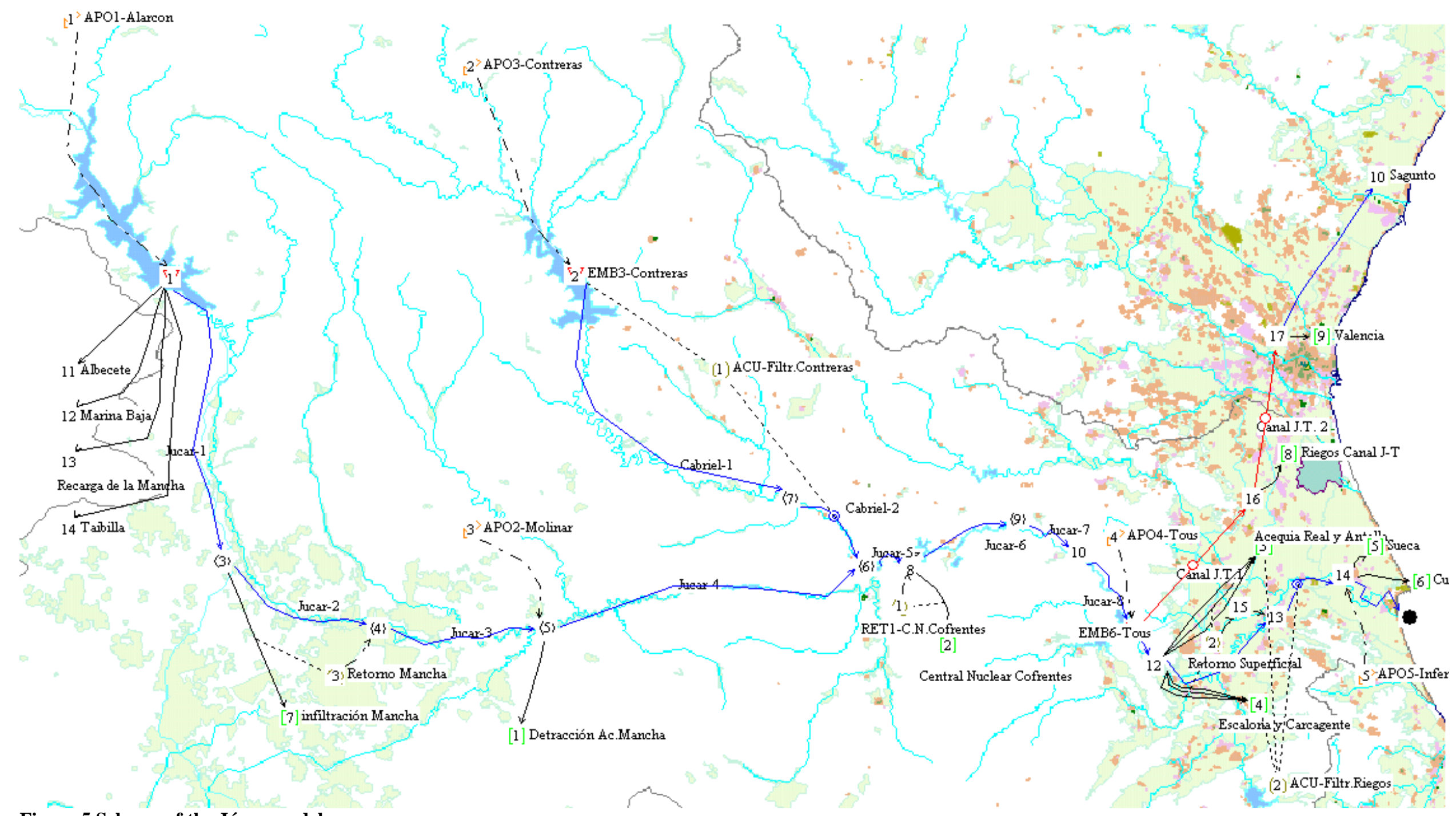

Figure 5.Scheme of the Júcar model 

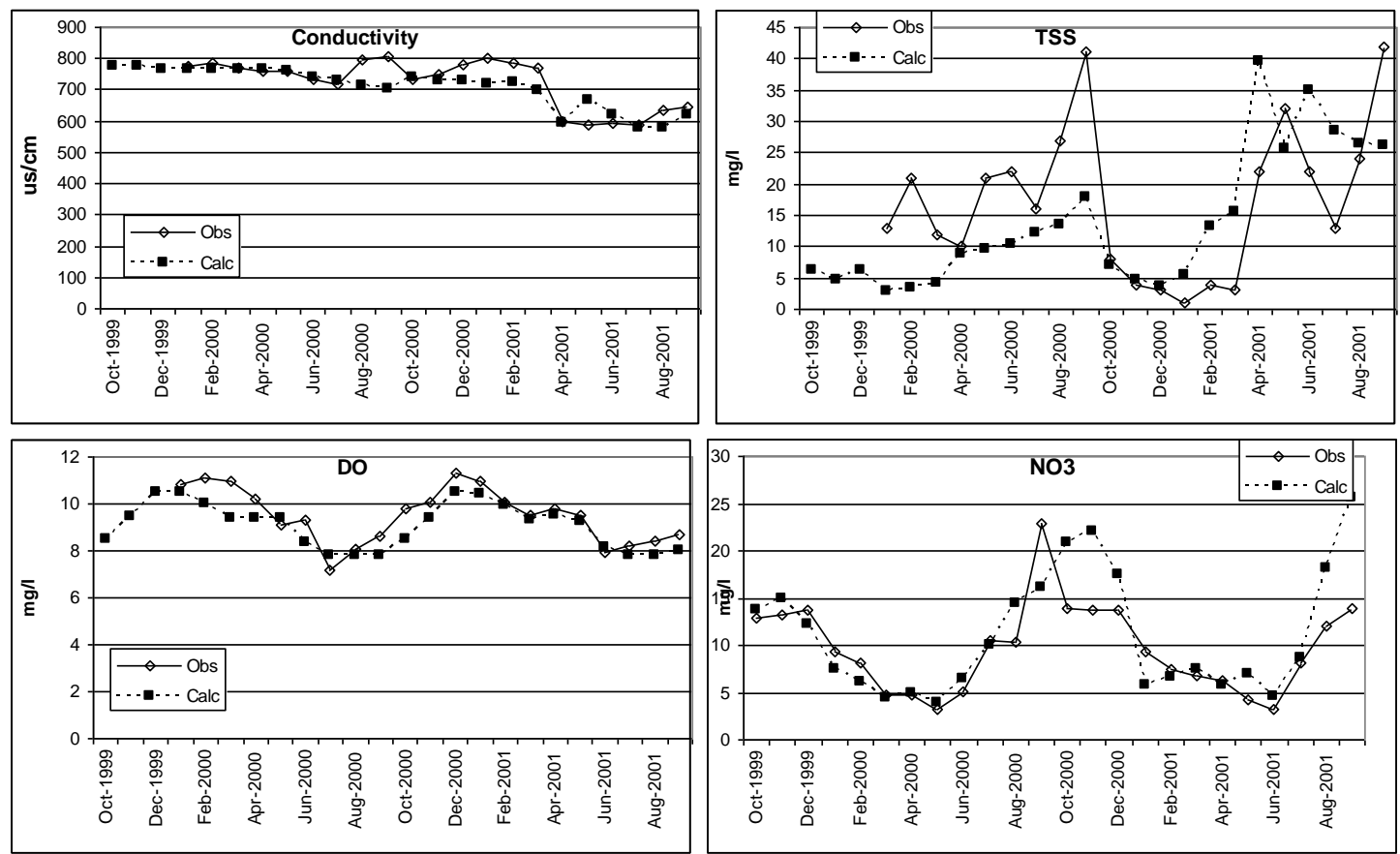

Figure 6. Calibration of a stream in the medium-low contaminated part of the river
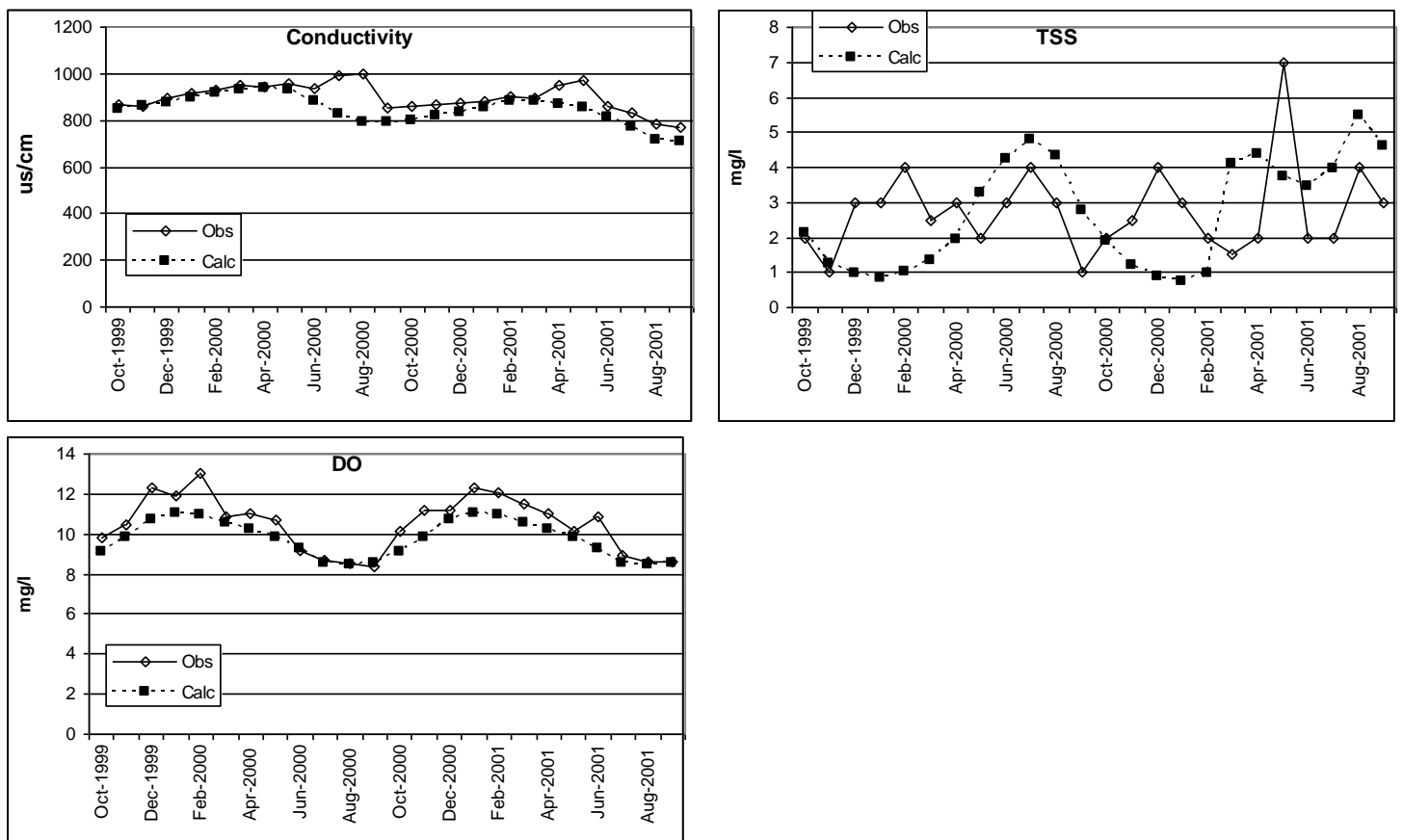

Figure 7. Calibration of Tous Reservoir 

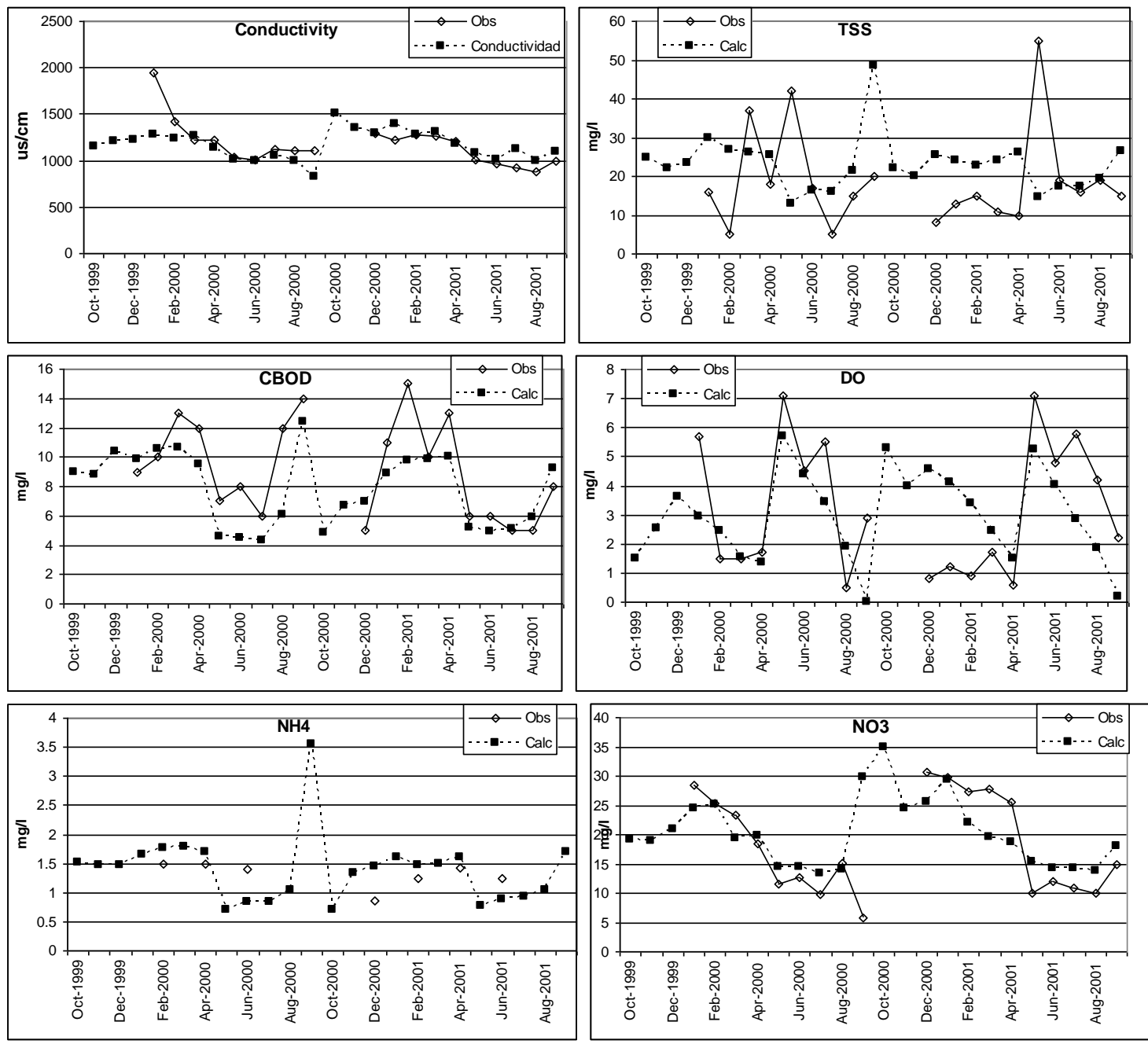

Figure 8. Calibration of a stream in the last-high contaminated part of the river 

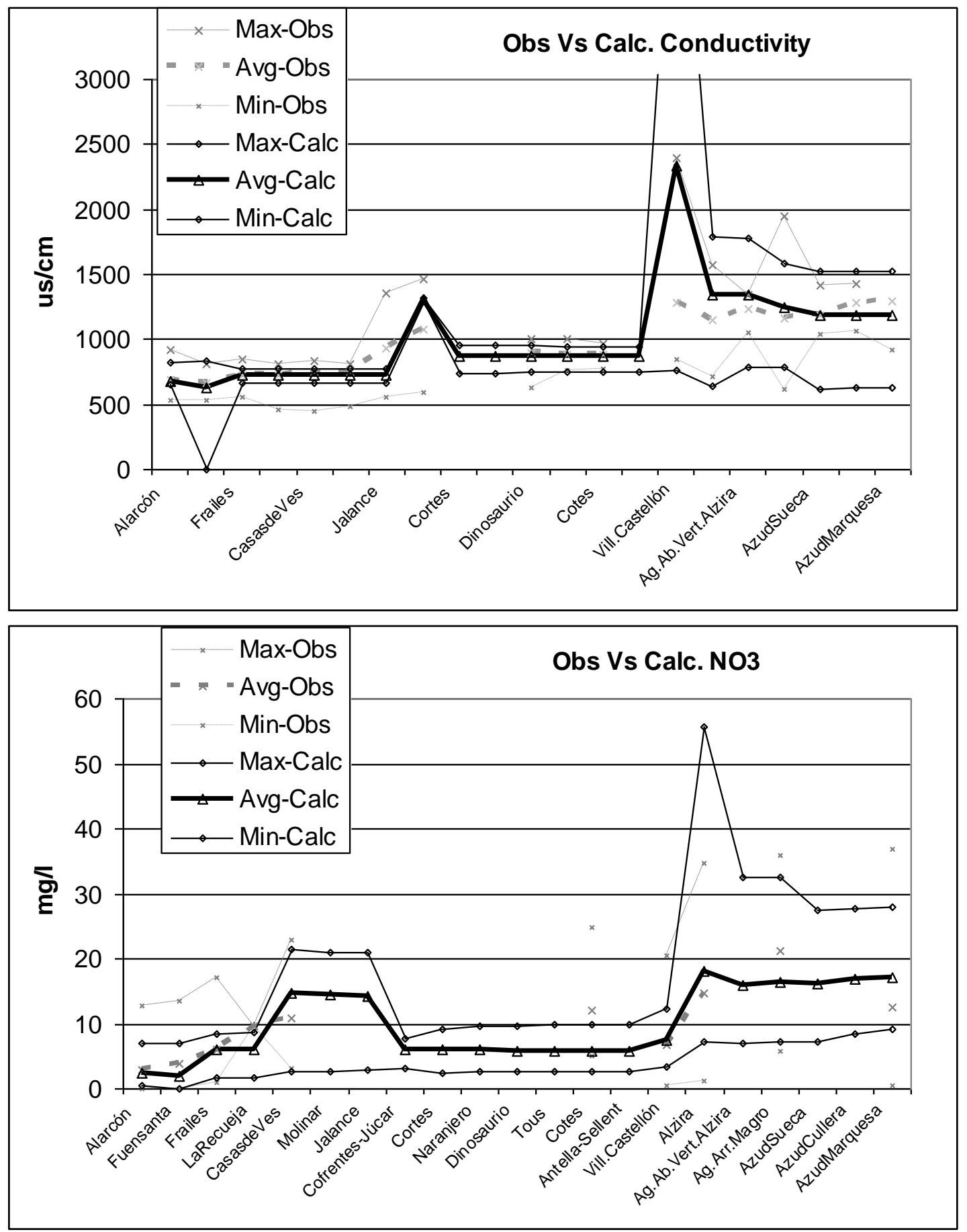

Figure 9. Calibration along the river 


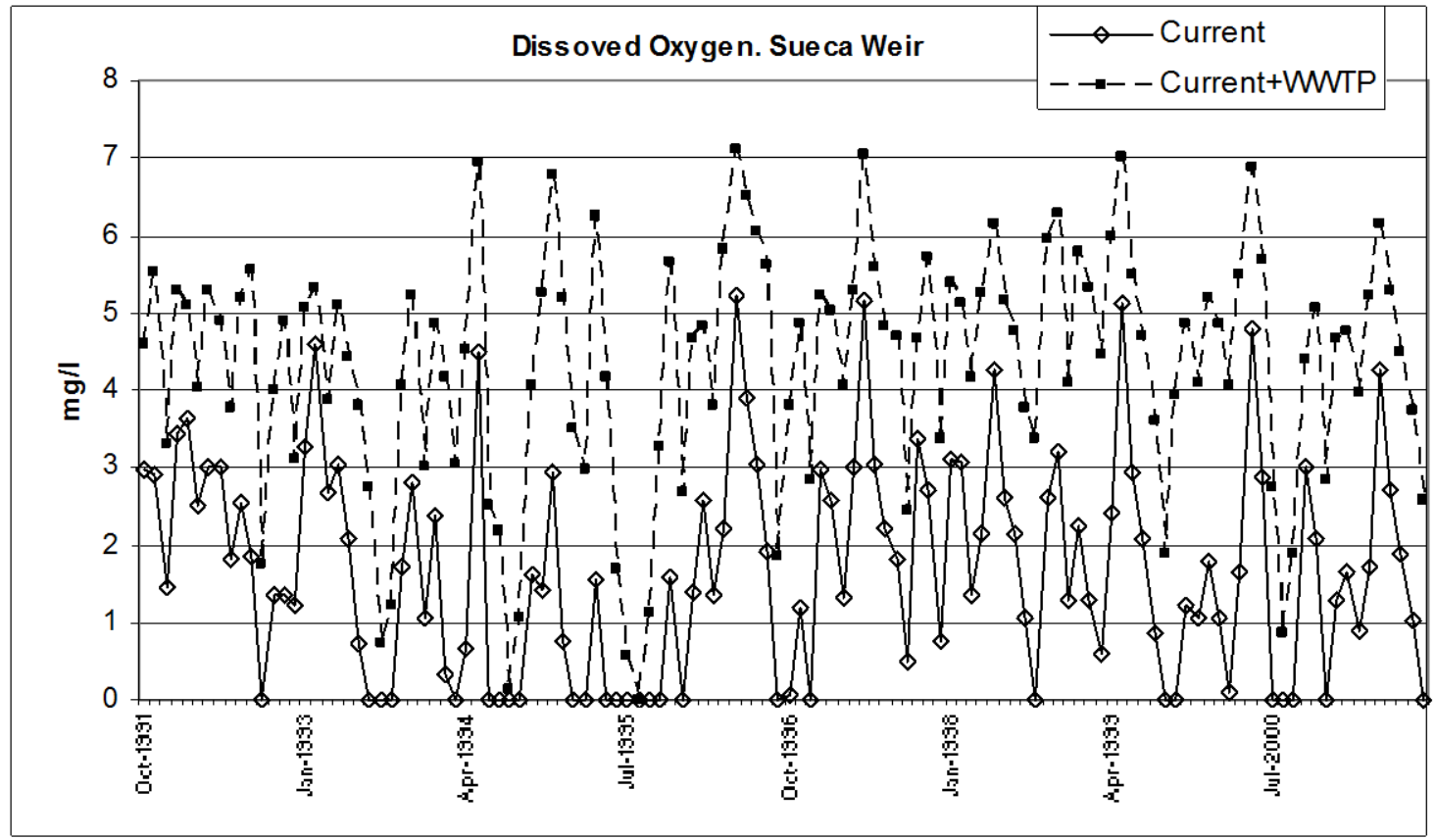

Figure 10. Dissolved Oxygen in Sueca Weir for Current and Current with WWTP scenarios.

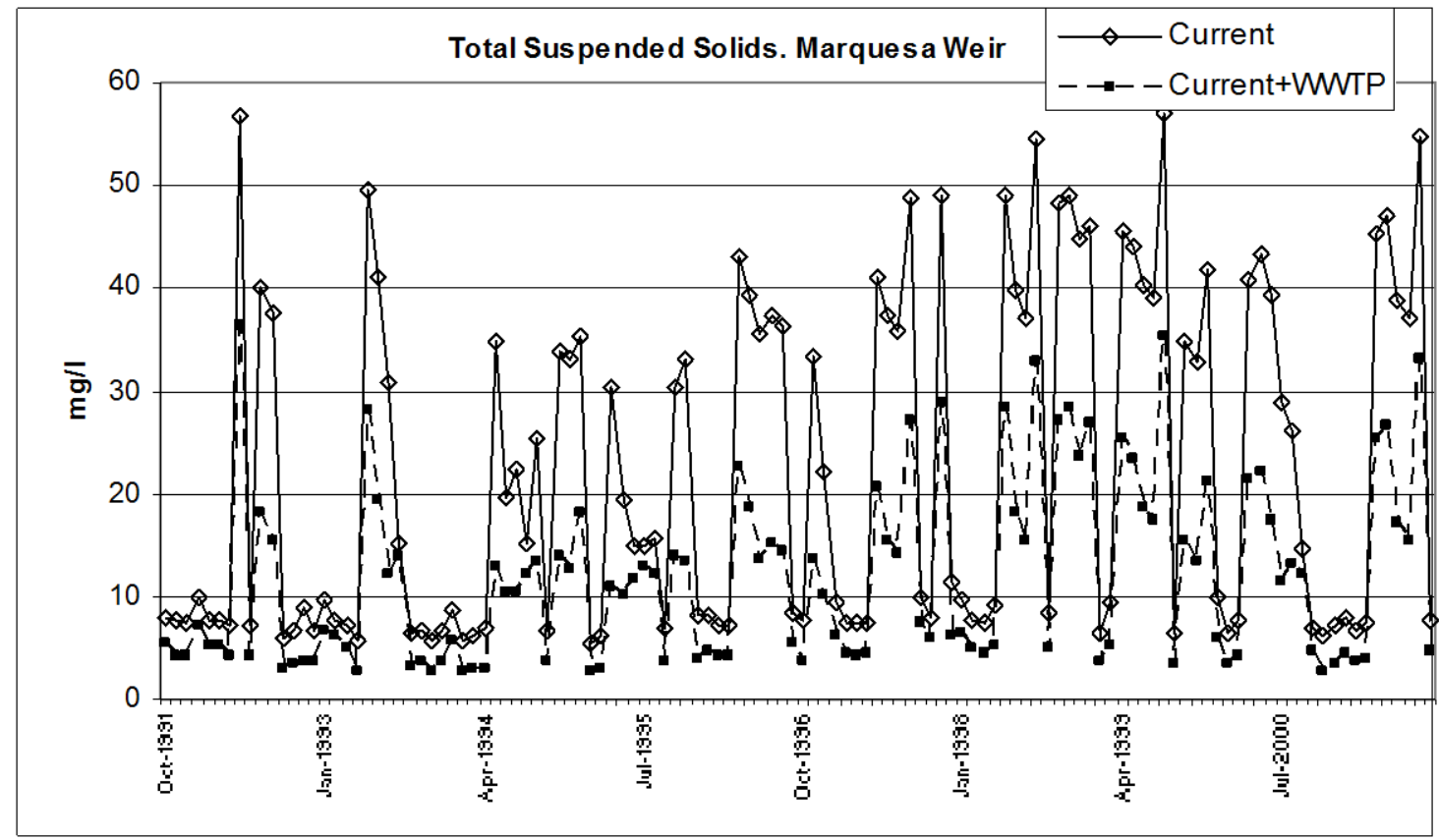

Figure 11. Total Suspended Solids in Marquesa Weir for Current and Current with WWTP scenarios 


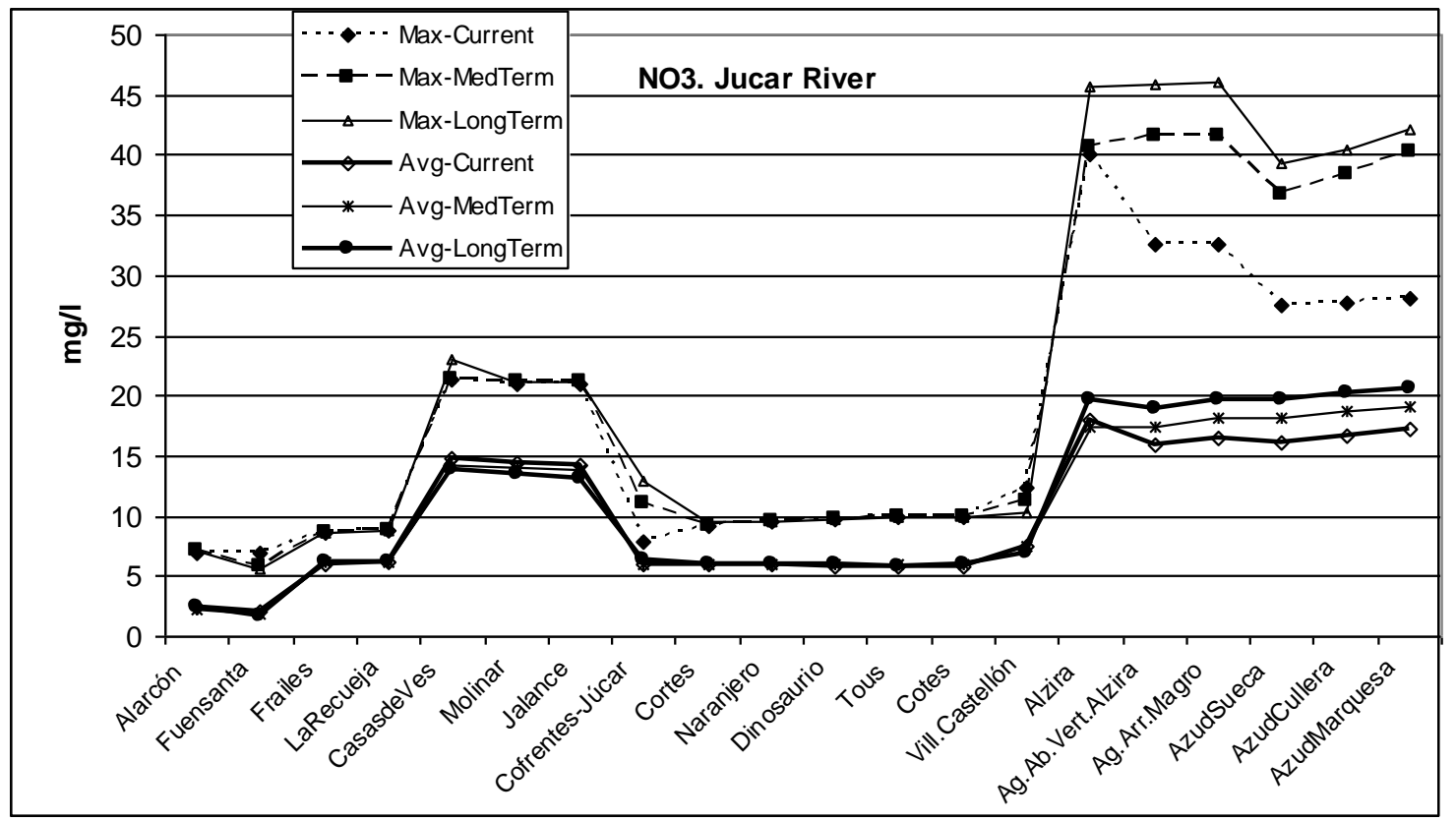

Figure 12. Average values along Júcar River of Nitrates concentrations.

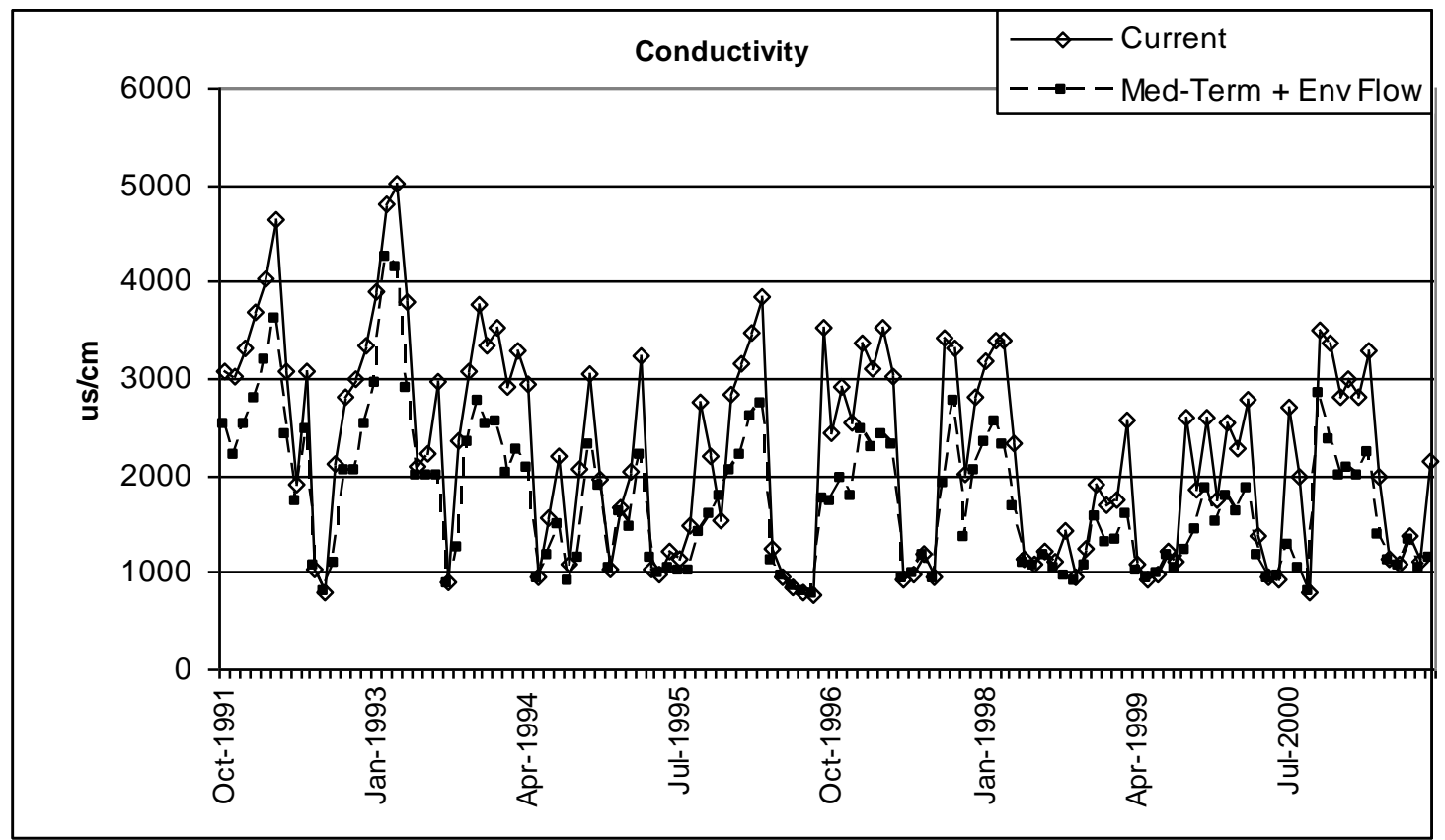

Figure 13. Estimated conductivity concentrations in the critical point. Effect of the environmental flows 


\begin{tabular}{|l|l|l|l|l|l|l|}
\hline & $V s$ & Ka & Kd & Knai & Knio & Kfosf \\
\hline Alarcon & 0.1 & 0.5 & 0.01 & 0.01 & 0.035 & 0.02 \\
\hline Molinar & 0.05 & 1.5 & 0.015 & 0.1 & 0.05 & 0.02 \\
\hline Contreras & 0.5 & 1.5 & 0.025 & 0.03 & 0.065 & 0.01 \\
\hline Cortes & 0.7 & 2 & 0.025 & 0.01 & 0.037 & 0.02 \\
\hline Naranjero & 0.7 & 2.2 & 0.03 & 0.01 & 0.035 & 0.025 \\
\hline Tous & 0.25 & 2.25 & 0.035 & 0.001 & 0.05 & 0.055 \\
\hline
\end{tabular}

Table 1. Reservoir calibrated parameters. Vs (m/d) Sedimen velocity suspended solids; Ka (1/d) reairation rate; Kd (1/d) CBOD degradation; Knai (1/d) organic nitrogen degradation; Knio (1/d) nitrification rate; Kfosf (1/d) phosphorous degradation.

\begin{tabular}{|c|c|c|c|c|c|c|}
\hline & Vs & Ka & $K d$ & Knai & Knio & Kfosf \\
\hline $\begin{array}{l}\text { Júcar upstream } \\
\text { merge Cabriel }\end{array}$ & $\begin{array}{l}0.002- \\
0.01]\end{array}$ & {$[0.2-1.5]$} & $\begin{array}{l}{[0.001-} \\
0.12]\end{array}$ & {$[0.001-0.1]$} & [0.01-0.12] & {$[0-0.12]$} \\
\hline $\begin{array}{l}\text { Júcar upstream } \\
\text { merger Cabriel. } \\
\text { Polluted streams }\end{array}$ & 0.15 & 1.2 & 0.35 & 0.2 & 0.65 & 0.2 \\
\hline Cabriel & $\begin{array}{l}0.002- \\
0.01]\end{array}$ & {$[0.2-1.5]$} & $\begin{array}{l}{[0.001} \\
0.12]\end{array}$ & {$[0.001-0.1]$} & [0.01-0.12] & {$[0-0.12]$} \\
\hline $\begin{array}{l}\text { Júcar medium } \\
\text { part of the river }\end{array}$ & $\begin{array}{l}{[0.01-} \\
0.1]\end{array}$ & {$[0.2-1.5]$} & $\begin{array}{l}{[0.001-} \\
0.25]\end{array}$ & [0.01-0.3] & [0.01-0.12] & {$[0-0.12]$} \\
\hline $\begin{array}{l}\text { Júcar Medium } \\
\text { part of the river, } \\
\text { high polluted }\end{array}$ & 0.015 & 1.5 & 0.015 & 0.25 & 0.18 & 0.9 \\
\hline $\begin{array}{l}\text { Júcar Medium } \\
\text { part of the river. } \\
\text { Higly polluted } \\
\text { streams }\end{array}$ & 0.27 & 2.2 & 1.2 & 0.75 & 0.85 & 0.2 \\
\hline
\end{tabular}

Table 2. Streams calibrated parameters. Vs (m/d) Sediment velocity suspended solids; Ka (1/d) reairation rate; Kd (1/d) CBOD degradation; Knai (1/d) organic nitrogen degradation; Knio (1/d) nitrification rate; Kfosf (1/d) phosphorous degradation. Values among brackets represents ranges. 
